\title{
Presentación
}

\section{Hacia un Sistema Escolar Inclusivo: Desde las Políticas a las Prácticas}

\section{Towards an Inclusive School System: From Policies to Practices}

\author{
Mónica Luna González * \\ Dirección Educación, I. Municipalidad de Peñalolén, Chile
}

La construcción de sistemas educativos inclusivos ha acompañado los procesos de reforma de los países de AL de desigual manera en las últimas décadas; pero resulta difícil hoy encontrar un discurso de política pública educativa que no se haga cargo de la inclusión, al menos en forma conceptual y teórica. Por lo mismo, los avances en la materia suelen tener distintos niveles de profundidad y arraigo dependiendo no sólo de los territorios nacionales a los que se aluda, sino también de sus capacidades para lograr acuerdos políticos y sociales sostenibles en el tiempo (lo que llamaríamos políticas de Estado), que no se vean amenazados por cambios de los gobiernos o se encuentren al arbitrio de mayorías relativas e intercambiables.

He aquí un primer desafío sobre el que dar cuenta, la inclusión educativa debe ser entendida como una realidad en construcción que requiere grandes acuerdos nacionales que se expresen en políticas de Estado al servicio de sociedades donde la dignidad de la persona humana y su vivencia en comunidad estén al centro de nuestras ocupaciones. Cabe recordar que tal dignidad, constituye la fuerza moral de la que todos los derechos fundamentales derivan su sustento (Habermas, 2010).

Un segundo desafío, no menor, lo constituye la tensión entre sistema educativo y su entorno social. Avanzar en inclusión educativa en contextos sociales altamente fragmentados, segregados y excluyentes supone un esfuerzo de perseverancia y optimismo casi patológico (Duk y Murillo, 2017), que debe ir siempre acompañado de la noción de educación como un sistema promovedor de transformación y justicia social. Este desafío nos recuerda la permanente tarea de la inclusión de visibilizar aquello que no se quiere ver y actuar sobre aquella realidad con afán de transformación.

Un tercer desafío, surge de la comprensión de las políticas públicas como cursos de acción y flujos de información relacionados con un objetivo público definido en forma democrática (...) desarrolladas por el sector público (...) con la participación de la comunidad y el sector privado. Una política pública de calidad incluirá orientaciones o contenidos, instrumentos o mecanismos, definiciones o modificaciones institucionales, y la previsión de sus resultados. (Lahera,2002). Lo anterior amplía la perspectiva que las políticas públicas sean solo materia de gobiernos, sino que expresan también la capacidad de los actores sociales de influir en la agenda pública presionando por cambios más efectivos y trascendentales. Por otra parte, abren la puerta a la responsabilización respecto a sus diseños e implementación, desde un permanente accountability, que otorgue

*Contacto: mluna@cormup.cl 
responsabilidad no solo frente a lo que fue diseñado, sino también de manera principal, respecto de lo implementado y posibles efectos no esperados.

Dicho esto, el diseño e implementación de políticas públicas inclusivas en materias educativas exige recordar una de las máximas weberianas de actuar siempre desde la ética de la responsabilidad, que nos obliga a hacernos cargo no solo de nuestras acciones, sino también de sus consecuencias.

Este número de la revista nos permite avanzar en ambas direcciones, haciéndose cargo de reflexionar sobre diseños y prácticas de políticas públicas inclusivas, asumiendo la radicalidad de la idea de inclusión como un mandato ético para la construcción de la realidad social. Por eso el recorrido que este volumen ofrece también la mirada sobre la tarea pendiente y las áreas donde es necesario avanzar.

Solo a modo de despertar el interés del lector mostramos con una mirada libre el recorrido de un camino en común:

- La mirada a la educación inclusiva de El Salvador, pone por delante la tarea de visibilizar las ausencias y exclusiones, afirmando la necesidad de modificar una visión sociocultural que desvaloriza y mantiene brechas. Lograr inclusión implica cambiar la cultura. Así es posible romper con el gatopardismo en estas políticas, donde todo cambia para que todo siga igual (Cristina Muñoz, El Salvador).

- La mirada de los profesores noveles frente a los desafíos de la inclusión educativa, nos advierte del peligro de responder desde lo necesario y posible (aunque no sea suficiente) y nos advierte que ello no solo es consecuencia de la condición de novel de los docentes, sino también de culturas escolares rígidas y burocratizadas (Tatiana Cisternas y Amparo Lobos, Chile).

- La mirada de los directivos escolares de la Araucanía frente a la inclusión de estudiantes migrantes pone de relieva la necesidad de un esfuerzo conjunto entre las políticas educativas y las actitudes de los actores del sistema. Se trata no sólo de cumplir mandatos desde una racionalidad técnica y formal, sino de transformar las culturas escolares, reconociendo el valor de la reciprocidad en la interculturalidad (Omar Aravena y otros, Chile).

- La mirada a la interculturalidad y bilingüismo en la educación de estudiantes sordos, nos acerca a la dimensión pedagógica y de innovación didáctica que se requiere para avanzar en el aprendizaje del español como segunda lengua. Se destaca la tarea de reconocer la visualidad y gestualidad como componentes de identidad, que deben ser valorados e incorporados en los procesos de innovación pedagógica para la comunidad sorda (Valeria Herrera y Verónica de la Paz, Chile).

- La mirada sobre la validación de un instrumento que permita medir percepciones de los docentes sobre el Diseño Universal de Aprendizaje nos recuerda la tremenda necesidad de contar con evidencia para la evaluación de instrumentos de política educativa que, profundizando en una mirada evaluativa, permitan su desarrollo permanente (Sergio Sánchez y otros, España).

- La mirada sobre la transversalización de la perspectiva de género en el espacio de las instituciones de educación superior nos recuerda un desafío compartido y 
plenamente vigente en todos nuestros países. Se muestra aquí la necesidad de avanzar a un conocimiento amplio y profundo de la perspectiva de género para todos los actores de las IES, mostrando un tremendo espacio de trabajo institucional y de desafío social y moral (Alejandra Montes, México).

Finalmente, poner por delante un riesgo para las políticas públicas inclusivas en educación (expandible por cierto a toda política pública): la inercia, que representa el riesgo de moverse siempre en un espacio insuficiente, pero conocido. Esa inercia que nos recuerda el concepto de TINA (There Is No Alternative) (Bauman y Donskis, 2016). Contra ello, recordemos que las políticas públicas no sólo deben moverse desde la ética de la responsabilidad; también deben tomar su fuerza de la ética de la convicción, que siempre será capaz de construir alternativas para transformar la realidad.

\section{Referencias}

Bauman, Z. y Donskis, L. (2016). La maldad líquida. Barcelona: Paidós.

Duk, C. y Murillo, F. J. (2018). Una investigación inclusiva para una educación inclusiva. Revista Latinoarmericana de Educación Inclusiva, 12(2), 11-13. https://doi.org/10.4067/S0718-73782018000200011

Habermas, J. (2010). El concepto de dignidad humana y la utopía realista de los derechos humanos. Diánoia, 55(64), 3-25. https://doi.org/10.21898/dia.v55i64.218

Lahera, E. (2002). Introducción a las políticas públicas. Santiago de Chile: Fondo de Cultura Económica. 